\title{
Population fluctuation of Fruit Flies and Effect of The Weather Factors on Their Activity and Infestation rates on guava fruits of summer and winter at fayoum governorate. \\ Amin, A. A. and M. H. Saafan \\ Plant protection Research Institute, ARC, Egypt
}

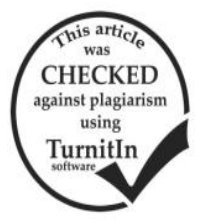

\begin{abstract}
This study was contributed for monitoring the population fluctuations and estimation of infestation rates of the peach fruit fly, Bactrocera zonata and the Mediterranean fruit fly, Ceratitis capitata on both summer and winter seasons of guava fruits at Fayoum governorate. The present investigation was conducted from $1^{\text {st }}$ week of August until end of March throughout the two successive seasons; 2014/2015 and 2015/2016. B. zonata was the most frequent and dominant species associated with guava at the experimental site during summer and winter seasons, while, $C$. capitata relatively appeared during the second season in summer (2015) and winter (2015/2016). The captured flies/trap/day (FTD) of B. zonata ranged between 0.59-5.57 and 0.16-7.81, in summer during the two seasons 2014 and 2015, respectively, while, C. capitata ranged between 0.17-8.97 flies/trap/day in summer during the second season (2015). Concerning in winter, FTD of B.zonata ranged between 0.03-0.86 and 0.01-3.10 flies/trap/day, for the two seasons 2014/2015 and 2015/2016, respectively, while, C. capitata ranged $0.26-4.94$ flies/trap/day during the second season(2015).In summer, maximum temperature was the variable weather factor significantly effect on the population of $B$. zonata during the first season, while the other weather factors correlated insignificantly effects. On the other hand, $C$. capitata, correlated with weather factors insignificantly during the two successive seasons. In winter, both of maximum and minimum temperatures effect significantly and positively on the population of B. zonata, while, the relative humidity had insignificantly positive effect during 2014/2015 season. During the second season (2015/2016), minimum temperature only had high-significantly in positive effect. Respecting C. capitata, during the first season (2014/2015), both of maximum and minimum temperatures effected insignificantly positive on the population, while, the relative humidity effected insignificantly and negatively on C. capitata population. While, in the second season, maximum and minimum temperature significantly effect in positive, whereas the relative humidity had high significantly negative correlation.In two summer periods during seasons (2014 and 2015), the highest infestation percentage (22.14 and 27.64\%, respectively) were recorded on first week of October, while, in the winter periods during the two seasons, fruits were free from fruit flies infestation. Forcing guava trees for fruiting during winter season during periods of relatively low fruit fly activity through some cultural practices like irrigation preventing and hand defoliation can be effectively employed to manage fruit fly infestations.
\end{abstract}

\section{INTRODUCTION}

Tephritid fruit flies are key pests of several fruit species, affecting crop yield, quality of harvested produce, and international market access (Aluja \& Mangan 2008). The peach fruit fly, Bactrocera zonata (Saunders) is one of the most destructive fruit flies that possessing a threat to many of Egypt's export markets and a more immediate threat to the welfare of the industry than the Mediterranean fruit fly, Ceratitis capitata (Wied.) and for this reason it's likely to prevent further spread (El-Heneidy, 2012).

Guava fruits are attacked by many species of fruit flies that found in almost all guava growing areas of the world. The summer season crop of guava fruits were exposed to many pests and diseases (Pena et al., 2002), particularly fruit flies which causes $25-50 \%$ loss to guava during summer (Syed, 1970 and Hashimi, 2001). B. zonata was reported to be the most frequent, constant and dominant species associated with guava(Sarwar et al., 2014).

At Fayoum governorate, guava trees are randomly distributed in minor areas or cultivated in scarce form as inter-planting mango areas. B. zonata populations are reaching high levels in July to September attacking guava fruits causing a significant damage coinciding maturation of guava fruits (Saafan et al., 2006, Afia, 2007, Amin, 2008 and Darwish et al., 2014). This causes great losses to the growers because the fruits are unmarketable. In addition, fruits have a cheap price and storability is very short due to fruits are being affected with high temperature in the summer season which causes browning colour of guava fruit , fast decay and its short shelf life to their fruits (El-Baz et al., 2011 and Naheed et. al., 2014).Moreover, removal of infested fruits as sanitation practice control of fruit flies is neglected by local farmers which causing severity to the next successive mature fruits, mainly citrus fruits.

Integrated Crop Management (ICM) practices may be defined as the utilization of all the possible practices of crop management in a manner as compatible as possible to increase crop yield through reducing pest population to a level below economic damage. Strategy of production during periods of relatively low fruit fly activity can be effectively employed to manage fruit fly infestations in fruit and vegetable crops (Sarwar, 2015). In Egypt, guava trees were forced to produce their fruits in winter season as affected by some agricultural practices, besides, guava fruits are desired to local market and aboard in winter. The winter crop of guava fruit trees from these treatments were good quality and its high price covered greatly the reduction in yield (El-Baz et. al., 2011 and Naheed et. al., 2014 ). This concept is based on the fact that guava flowers are borne only on new, succulent, vigorously emerging vegetative growths. These new growth flushes can be either new emergences of lateral bud on older stems or extensions of already established terminals of various size and vigor (Boora et. al., 2016).

Therefore, the present studies contributed for monitoring the population fluctuations and estimation of infestation rates of the peach fruit fly and the Mediterranean fruit fly on both summer and winter guava fruits at Fayoum governorate. Also, evaluating of defoliation as cultural practice on guava trees in order to 
be employed on ICM strategies to be applicable at areas likely to Fayoum conditions.

\section{MATERIALS AND METHDOS}

\section{A- Selection of the Experimental Orchards:}

The present investigations were conducted from the first week of August until the end of March throughout summer and winter of 2014/2015 and 2015/2016 seasons at Fayoum governorate in guava orchards located at Senro (El-Haragawya), Ibshway district. The selected guava orchards were surrounded by an area of about 100 feddans cultivated mainly with mango, guava, and citrus including mainly mandarin. The guava trees that were forced for fruiting during winter season were prevented from irrigation for four months (First July until end October) and defoliation process was done by hand.

\section{B-Monitoring of $B$. zonata and $C$. capitata Populations:}

For monitoring B. zonata males, six Jackson sticky traps (according to Harris et al., 1971) were baited with a mixture of methyl eugenol (as a male lure of $B$. zonata ) and malathion (as a toxicant agent) in ratio of 8:2, respectively. Also, an equivalent number of the same trap were baited with trimedlure (as male lure of $C$. capitata ). The traps were hung at a height approx., $1.75-2.50 \mathrm{~m}$. and alternatively distributed in the orchards at about $50 \mathrm{~m}$ distance. Traps were inspected weekly with replacing the sheets and replenished with the mentioned attractants by injection the cotton wick by medical syringe. The attracted males of both fruit flies were counted and the mean captured flies per trap per day "FTD" was calculated.

\section{C- Assessment Infestation Percentage:}

Infestation symptoms of both fruit flies are so similar to be individually distinguished for each of them, therefore, the infestation percentages was estimated for both fruit flies together. For each fruiting season of guava trees, 5 trees were selected and 40 fruits at least representing on the cardinal directions of the trees, preferably mature, were weekly inspected. A fruit was considered damaged when a fly ovipuncture or watery spot was visible (Vayssiéres et al., 2009). The infestation percent damage was determined as ratio of number of infested fruits per total of inspected fruits.

Fruit samples were performed at weekly intervals of fresh guava fruits that were picked up from trees or collected from fallen fruits. The collected fruits were brought to the laboratory in plastic bags and placed in plastic containers after counting above a layer of sterilized sand $(10 \mathrm{~cm})$. After 3-5 days during summer season and 15-25 days during winter season, the fruits were inspected for fruit flies. All pupae were obtained from sand by sieving and the numbers of produced pupae were counted and kept in Petri dishes. The emerged adults of each species of fruit flies were counted.

\section{D- Statistical Analysis:}

Data obtained was subjected to multiple regression analysis using SPSS ${ }^{\circledR}$ software programme (ver. 19) .

\section{RESULTS}

\section{Population Fluctuation of Peach Fruit Fly and Mediterranean Fruit Fly:}

The population fluctuations of both fruit fly species were investigated for the two successive seasons, 2014/2015 and 2015/2016 on guava fruits at Fayoum governorate. The field experimental studies were designed to start one month before fruit maturity at least.

\section{Guava Fruiting Summer Season:}

Data in Fig. (1) present the population fluctuations of both fruit flies during summer season of guava fruits at Fayoum governorate during the two successive seasons of 2014 and 2015.

The first season (2014):

$B$. zonata population on guava fruits started with a FTD value of 4.16 flies/trap/day on the $1^{\text {st }}$ week of August followed by remarkable increase to show the highest peak of 5.57 flies/trap/day during the $3^{\text {rd }}$ week of August. Hence, population gradually decreased during the last two weeks of August to record the lowest density of population on the ultimate week of August recording a FTD $=0.59$ male / trap / day). Then, the population fluctuated in increase during the $1^{\text {st }}$ and $2^{\text {nd }}$ weeks of Oct. to record a FTD value of 1.94 flies/ trap / day. After that, the population differently fluctuated with low FTD values during the months of September and October.As mentioned above, the remarkable increase on guava may be due to the emerged flies from the previously intercropping infested mango fruits. While, the remarkable increase of $B$. zonata population during September and October may be due to emerged flies of early matured guava fruits.

Regarding $C$. capitata population, traps recorded flies only during the $1^{\text {st }}$ and $2^{\text {nd }}$ weeks of August in in low values of FTD. ( 0.10 and 0.06 male/ trap/day, respectively). Afterwards, C. capitata flies completely disappeared until end of the season. $C$. capitata population was observed in low numbers which were unable to compete $B$. zonata for infesting fruits.

The second season (2015):-

Contrary to the previous season, $B$. zonata population started with a low value of FTD (0.16 fly/ trap/day) on the $1^{\text {st }}$ week of August Meanwhile, the population gradually increased to reach the highest peak on the last week of September with a FTD value of 7.81 flies/trap/day followed by a sharp decrease to the end of investigation period with FTD value of 2.49 flies/trap/day. On the other hand, $C$. capitata population started with the highest value of FDT (8.97 flies/trap/day) followed by remarkable decrease until the end of August. After that, the population began to increase showing the high density of population that could be coinciding with the period of maturation and ripening of guava fruits on the $3^{\text {rd }}$ week of September $(\mathrm{FTD}=4.06$ flies/trap/day). While, the population differently fluctuated to the end of season to record a FTD value of 2.31 flies/trap/day on the last week of October. 
The first season (2014)
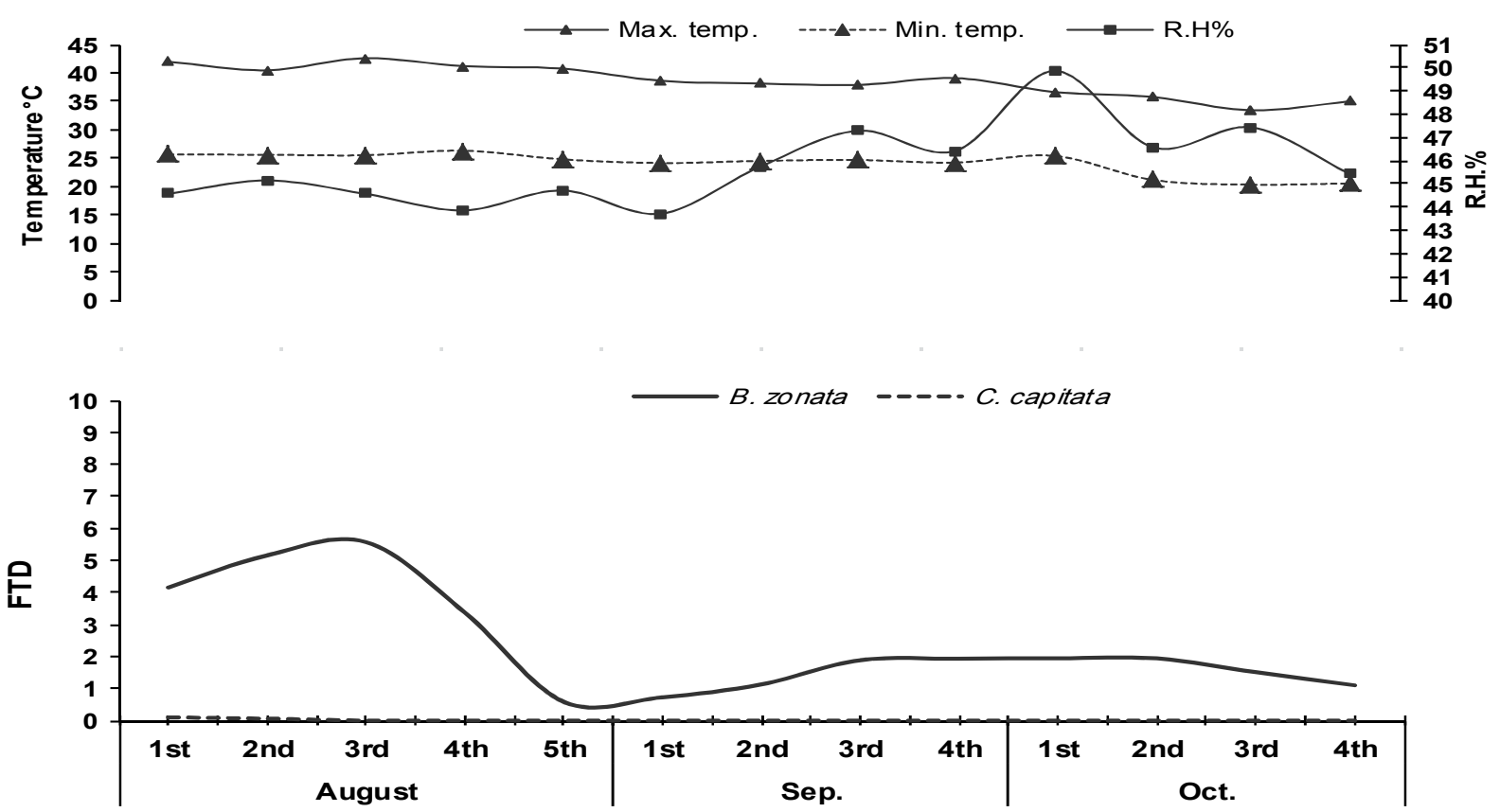

Date of inspection

The second season (2015)
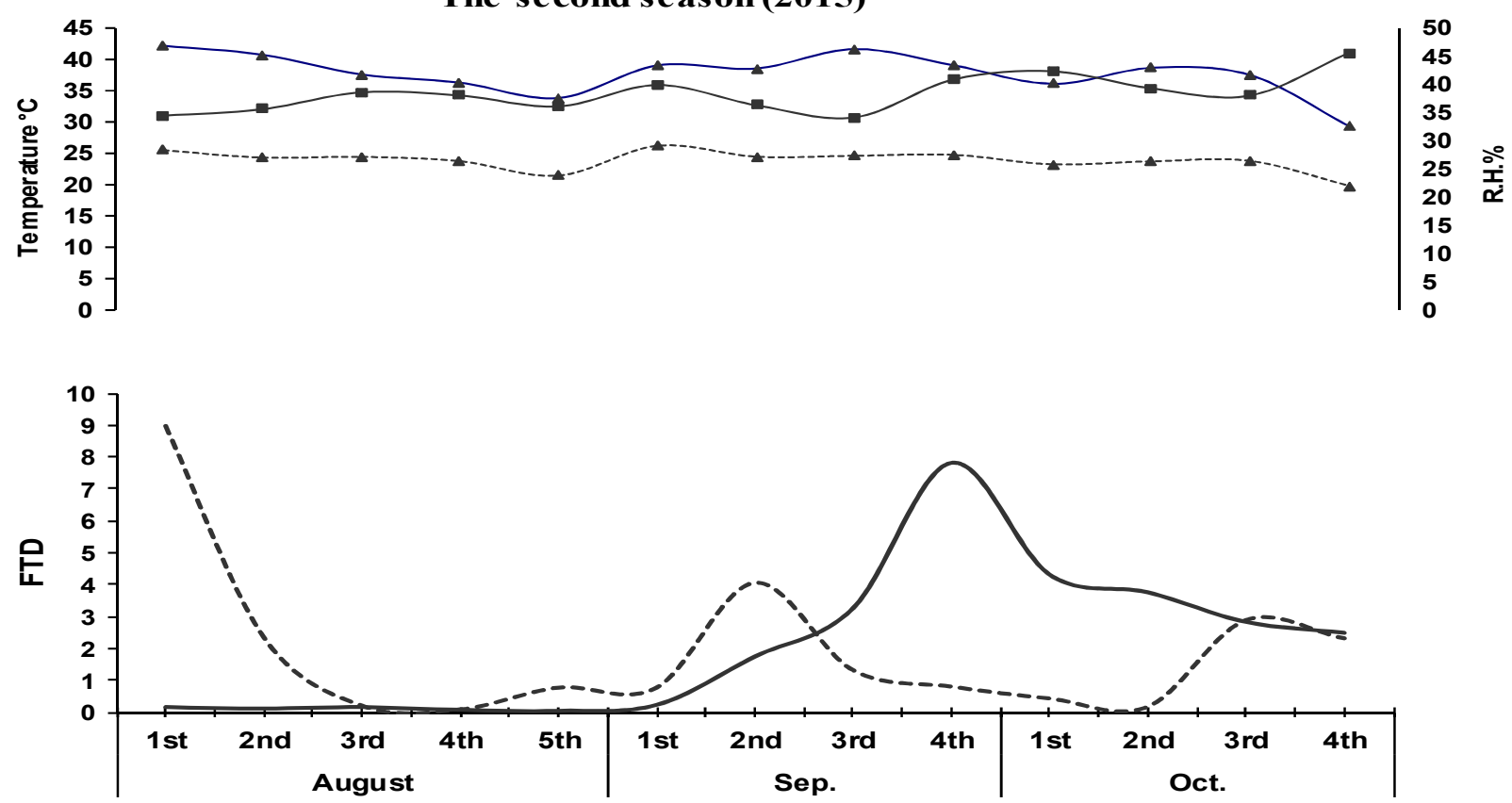

Date of inspection

Fig. 1. Mean of weekly captured males of $B$. zonata and $C$. capitata in guava summer fruiting season and weekly means of Max., Min. temp. and R. H.\% at Fayoum governorate during the two seasons of 2014 and 2015

\section{Guava Fruiting Winter Season:}

Data in Fig. (2) represents the population fluctuations of both fruit fly species during winter season at Fayoum governorate during the two successive seasons of 2014/2015 and 2015/2016.
The first season $(2014 / 2015)$ :

The population of $B$. zonata, began to observe with a FTD of 0.77 value in the $1^{\text {st }}$ week of November and it differently fluctuated to reach the highest value of FTD ( $0.86 \mathrm{fly} /$ trap/day) on the $3^{\text {rd }}$ week of November. Then, a gradual decrease was observed during December showing a low peak (0.29 fly/trap/day) on the 
$3^{\text {rd }}$ week of December. After that, the population decreased to disappear completely from the last week of January. It should be remember that guava fruits in ripening stage are preferable for infestation by both flies, however, the low temperature throughout this period maybe responsible for such mentioned population decline of $B$. zonata in the $2^{\text {nd }}$ week of January. On the other hand, the population of $C$. capitata completely disappeared during the period of the investigation excepting the weeks of March coinciding with temperature raising which recording $26.9^{\circ} \mathrm{C}$ and $11.5^{\circ} \mathrm{C}$ of max., and min., temp., respectively.

The second season $(2015 / 2016)$ :

During the second season, the individuals of $B$. zonata started to be investigated with a FTD value of 3.10 flies on the $1^{\text {st }}$ week of November, followed by a marked increase on the $2^{\text {nd }}$ week of November to reach a FTD of 3.81 flies (recording the highest peak). After that, the population gradually decreased till the $2^{\text {nd }}$ week of December. But, it increased again showing medium peak on the pre-ultimate week of the same month. After that, the population differently fluctuated at low values of FTD. This reduction in B.zonata population may be due to the low temperature during winter season.

Respecting C. capitata, individuals of this species were observed with various FTD values throughout the period of investigation. On the $1^{\text {st }}$ week of November, males of C. capitata were recorded in traps with low value of FTD (1.63). The population sharply increased to record the highest peak of 4.94 flies/trap/day on the $3^{\text {rd }}$ week of November. After that, the population of $C$. capitata drastically decreased to show differently low fluctuated FTD values till the $2^{\text {nd }}$ week of February. Then, the population began to gradually increase showing the last and median peaks of FTD values of 2.97 flies/trap/day on the $4^{\text {th }}$ week of March.

\section{Effect of the Weather Factors on the Activity:}

The relationship between the population of $B$. zonata and C. capitata adults (estimated as FTD) for guava of both summer and winter seasons and the prevailing weather factors (weekly means of both maximum and minimum temperature and relative humidity) was studied throughout the two seasons of 2014/2015 and 2015/2016 (Table 1 ).

\section{Guava Fruiting Summer Season:}

As shown in Table (1), the population of $B$. zonata only positively and significantly correlated with mean of maximum temperature $(\mathrm{r}=0.606)$ during the first season. The other tested weather factors insignificantly affect the population of both $B$. zonata and $C$. capitata during the periods of investigation of the two successive seasons (2014 and 2015). For $B$. zonata, the coefficients of determination $(\mathrm{R})$ for both two seasons were found to be significant $(R=0.649)$ for $1^{\text {st }}$ season and insignificant $(R=0.210)$ for the $2^{\text {nd }}$ season. The combined effect of the tested weather factors was responsible for 42.12 and $4.41 \%$ of the peach fruit fly population for the two successive seasons, 2014 and 2015, respectively. While, for $C$. capitata, the coefficients of determination $(\mathrm{R})$ for the $1^{\text {st }}$ and $2^{\text {nd }}$ seasons were found to be insignificant $\left(R \_0.452\right.$ and 0.433 , respectively). The combined effects of the examined weather factors were responsible for 20.43 and $18.75 \%$ of population changes.

Table 1. Simple correlation and multi factor-regression analysis between population of $B$. zonata and $C$. capitata, and the weather factors (Max. temp., min. temp. and R. H. \%) for the two seasons 2014/2015 and 2015/2016 at Fayoum governorate.

\begin{tabular}{|c|c|c|c|c|c|c|c|}
\hline Season & & $\begin{array}{l}\text { Fruit fly } \\
\text { species }\end{array}$ & $\begin{array}{l}\text { Predictors } \\
\text { variables }\end{array}$ & $\mathbf{r}$ & $p$ & $\mathbf{R}$ & $\begin{array}{c}\text { Combined } \\
\text { Effect } \%\left(R^{2}\right)\end{array}$ \\
\hline \multirow{11}{*}{ 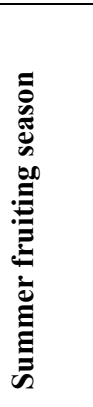 } & \multirow{6}{*}{ 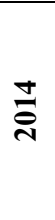 } & \multirow{3}{*}{ B. zonata } & Max. temp. & $0.606^{*}$ & 0.695 & \multirow{3}{*}{0.649} & \multirow{3}{*}{42.12} \\
\hline & & & Min. temp. & 0.485 & -0.373 & & \\
\hline & & & R.H.\% & -0.214 & 0.354 & & \\
\hline & & \multirow{3}{*}{ C.capitata } & Max. temp. & 0.435 & 0.008 & \multirow{3}{*}{0.452} & \multirow{3}{*}{20.43} \\
\hline & & & Min. temp. & 0.325 & -0.005 & & \\
\hline & & & R.H.\% & -0.223 & 0.003 & & \\
\hline & \multirow{6}{*}{$\frac{n}{2}$} & \multirow{3}{*}{ B. zonata } & Max. temp. & 0.004 & 1.345 & \multirow{3}{*}{0.210} & \multirow{3}{*}{4.41} \\
\hline & & & Min. temp. & -0.040 & -1.686 & & \\
\hline & & & R.H.\% & 0.443 & .0907 & & \\
\hline & & \multirow{3}{*}{ C.capitata } & Max. temp. & 0.337 & 0.276 & \multirow{3}{*}{0.433} & \multirow{3}{*}{18.75} \\
\hline & & & Min. temp. & 0.203 & -0.395 & & \\
\hline \multirow{13}{*}{ 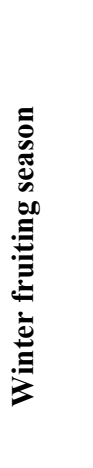 } & & & R.H.\% & -0.0415 & -0.201 & & \\
\hline & \multirow{6}{*}{ 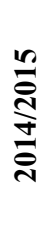 } & \multirow{3}{*}{ B. zonata } & Max. temp. & $0.625 * *$ & -0.003 & \multirow{3}{*}{0.820} & \multirow{3}{*}{67.24} \\
\hline & & & Min. temp. & $0.820 * *$ & 0.084 & & \\
\hline & & & R.H.\% & 0.233 & 0.001 & & \\
\hline & & \multirow{3}{*}{ C.capitata } & Max. temp. & 0.208 & 0.003 & \multirow{3}{*}{0.281} & \multirow{3}{*}{7.90} \\
\hline & & & Min. temp. & 0.086 & -0.001 & & \\
\hline & & & R.H.\% & -0.210 & -0.003 & & \\
\hline & \multirow{6}{*}{ 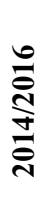 } & \multirow{3}{*}{ B. zonata } & Max. temp. & 0.319 & -0.146 & \multirow{3}{*}{0.766} & \multirow{3}{*}{58.67} \\
\hline & & & Min. temp. & $0.631 * *$ & 0.463 & & \\
\hline & & & R.H.\% & 0.051 & 0.086 & & \\
\hline & & & Max. temp. & $0.635 * *$ & 0.007 & \multirow{3}{*}{0.713} & \multirow{3}{*}{50.83} \\
\hline & & C.capitata & Min. temp. & $0.698 * *$ & 0.268 & & \\
\hline & & & R.H.\% & $-0.444^{*}$ & -0.055 & & \\
\hline
\end{tabular}


Guava Fruiting Winter Season:

For B. zonata, a high significantly and positively correlation was shown between the population and both max. and min. temperatures $(r=0.625$ and 0.820 respectively) during 2014/2015 season, while, the relative humidity had insignificantly positive effect $(\mathrm{r}=$ 0.233). But, during the $2^{\text {nd }}$ season, minimum temperature only had high-significantly in positive effect $(r=0.631)$. The coefficients of determination ( $R$ ) for both two periods were found to be significant $(\mathrm{R}=$ 0.820 and 0.766 ) for the $1^{\text {st }}$ and $2^{\text {nd }}$ seasons, respectively, the combined effect of the prevailing weather factors were responsible for 67.24 and $58.67 \%$ of the fly population for the two successive seasons, respectively.

Respecting $C$. capitata, statistical analysis of the $1^{\text {st }}$ season (2014/2015) showed an insignificantly positive correlation between the population and both of max. and min. temperatures $(r=0.208$ and 0.086 , respectively), while an insignificant negative correlation was shown between the relative humidity and $C$. capitata population $(\mathrm{r}=-0.210)$. While, in the $2^{\text {nd }}$ season, highly-significance positive correlation is shown between the maximum temperature minimum temperature with $C$. capitata population $(\mathrm{r}=0.635$ and 0.698 ), whereas the relative humidity had high significantly negative correlation $(r=-0.444)$. The coefficients of determination $(\mathrm{R})$ for the $1^{\text {st }}$ season (2014/2015) was found to be insignificant $(R=0.281)$, while it was significant $(\mathrm{R}=0.713)$ for the $2^{\text {nd }}$ season (2015/2016). The combined effect of the examined weather factors were responsible for 7.90 and $50.83 \%$ of the population for the two successive seasons, respectively.

Percentages of fruit infestation:

Data in Table (2) show the infestation percentages and emerged flies of both $B$. zonata and C. capitata on guava fruits at Fayoum governorate during two seasons of 2014/2015 and 2015/2016.

Table 2. Fruit infestation \% and mean no. of emerged adults of fruit flies of guava fruits during summer and winter seasons at Fayoum governorate during the two seasons of 2014 and 2015.

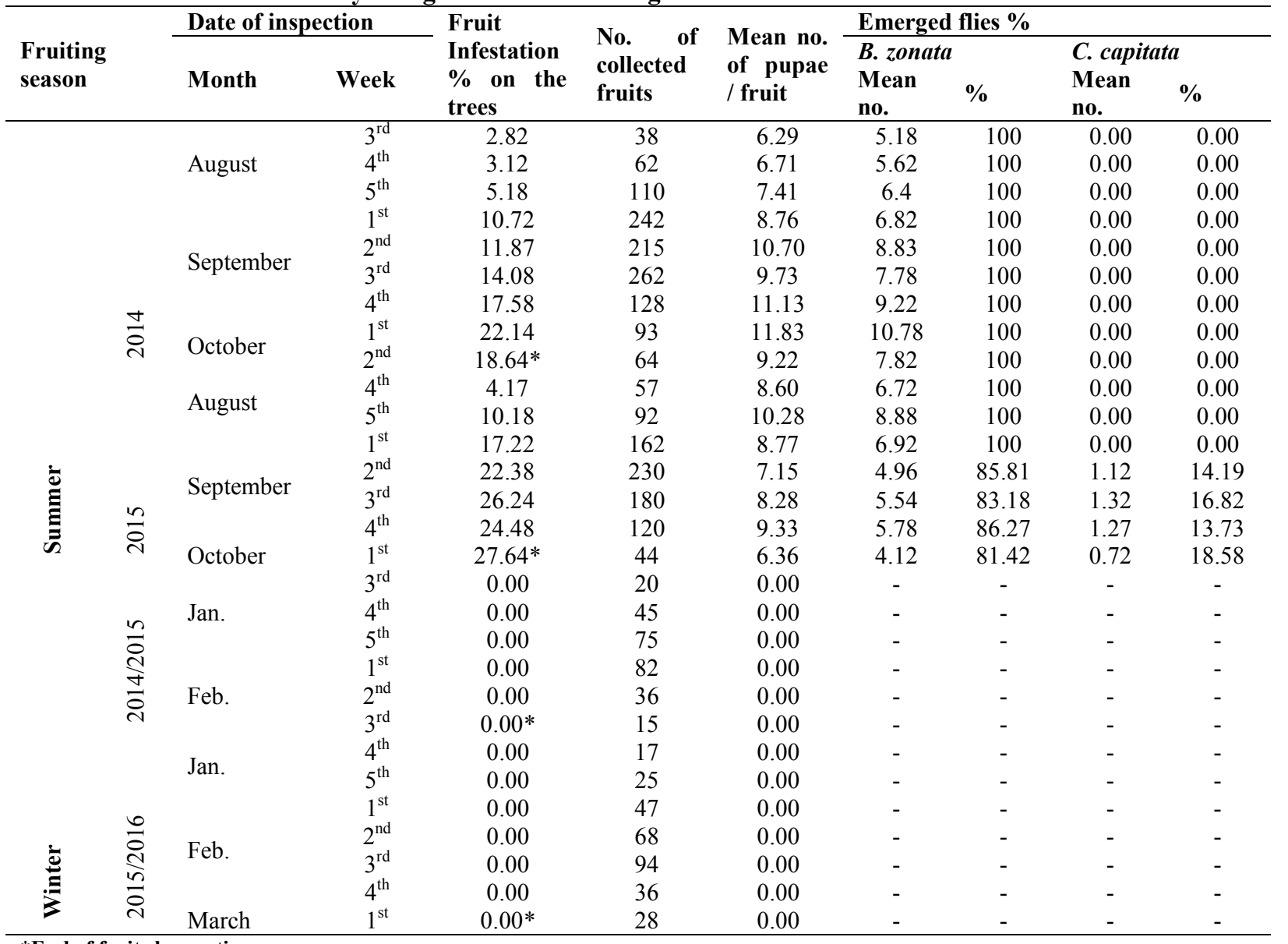

*End of fruits harvesting

Concerning infestation rate of B. zonata and $C$. capitata, a gradual increase could be observed related to progressive development of fruit ripening in all samples of the studied two seasons. During the $1^{\text {st }}$ season of summer fruits (2014), the $1^{\text {st }}$ infestation was observed during the $3^{\text {rd }}$ week of August with a percent of 2.82 followed by a gradual increase to reach the highest infestation percentage $(22.14 \%)$ in the $1^{\text {st }}$ week of October.

All emerged flies from collected fruits were belonging to $B$. zonata, thus indicating that all fruit infestations could be occurred by $B$. zonata only. While, during the $2^{\text {nd }}$ season, the infestation began to observe on the $4^{\text {th }}$ week of August and gradually increase to 
record the highest percentage of infestation on $1^{\text {st }}$ week of October $(27.64 \%)$. The emerged flies of collected fruits during both $4^{\text {th }}$ and $5^{\text {th }}$ weeks of August as well as the $1^{\text {st }}$ week of September were belonging to B. zonata, while, $C$. capitata emerged during the rest weeks of fruit sampling in low rate compared to B. zonata.

Contrary to the previous results, the infestation $\%$ of fruit flies during the two successive seasons of winter fruiting guava was nil. All the collected samples either that collected from the trees or that fallen under the trees were found to be free from larvae of fruit flies during the period of investigation.

\section{DISCUSSION}

Guava fruits are one of the most favorable host of fruit flies and availability a numerous numbers of fruit flies during its maturity and ripening stages is common situation. Summer guava fruits recorded high levels of infestation with both $B$. zonata and $C$. capitata compared to that reported during the winter season. The obtained results are going in agreement with those reported previously by Saafan et. al., (2006), Afia, (2007), Amin (2008) and Sarwar et. al.,(2014). The effect of weather factors on population of fruit flies during summer season insignificantly varied, thus indicating that these weather factors were not entirely the major factors that controlling the population fluctuations of both fruit flies (Afia, 2007 and Amin, 2008), guava rate of maturation was the most independent variables for attracting $B$. zonata adults during summer season (Darwish et al., 2014). However, most of those investigators concluded that weather factors particularly, temperature, relative humidity, sunlight, rainfall and soil temperature are significantly correlated with population fluctuation of fruit fly species.

Guava fruits of summer season are exposed to many pests, particularly fruit flies which cause significant damage (Syed, 1970; Hashimi, 2001 and Pena et al., 2002,). B. zonata was reported to be the most frequent, constant and dominant species associated with guava (Sarwar, 2015). Previous studies indicated the absolute dominance of $B$. zonata as an invasive fruit fly over $C$. capitata as a native fruit fly indicating by the entirely emerged adults of infested fruits (Saafan et., al., 2006 and Amin 2008). Also, in Pakistan, B. zonata was reported to be dominant in guava orchards over the oriental fruit fly, B. dorsails (Sarwar et al., 2014).Also, it is agree with that reported by El-Kousy et al., (2012) who recorded the emerged $B$. zontata flies was equal 6.71 fold of $C$. capitata. Such relative appearance of $C$. capitata maybe due to efforts of the National area eradication program of fruit flies for suppression populations of $B$. zontata through Male Annihilation Technique applications.

The winter guava fruits revealed incidence of a low numbers of both fruit flies in comparison to that observed during summer season, subsequently, reduction of infestation percentage was probable. However, fruits were observed to be free of infestation during the successive two seasons. The captured males represented the overwintering generation that emerged from navel orange and mandarin fruits in prior periods. Clearly, the low temperature may be is the main factor that influencing population densities of both flies during winter season that resulting of citrus infested fruits and probably present the overwintering individuals. Such suppose could be acceptable during the $1^{\text {st }}$ season (2014/2015), whereas a fewer numbers of both fruit flies were observed. While, during the $2^{\text {nd }}$ season (2015/2016), availability of two fruit flies populations' could be observed.

In order to understand the inability of fruit fly adult to attack guava fruits, Afia (2007) reported some biological aspects that may be demonstrate the current status. The range of temperature $20-35^{\circ} \mathrm{C}$ was the suitable for preoviposition period of B. zonata, while, the range of $15-30^{\circ} \mathrm{C}$ was suitable for $C$. capitata. The oviposition period was generally longer for $C$. capitata than $B$. zonata at low temperature $\left(15-30^{\circ} \mathrm{C}\right)$. In other words, the available temperature may be not suitable for completion of sexual maturity and also inhibiting the flies activity. Moreover, Ducky et al. (2004) reported that no ovarian maturation of $B$. zonata was observed at 15,20 and $35^{\circ} \mathrm{C}$ when rearing on 5 constant temperature, ovarian maturation was obtained only over a very narrow range of temperature $\left(25-30^{\circ} \mathrm{C}\right)$. Fletcher (1989) mentioned that temperature plays a dominant role in the rate of development of immature stages of $B$. zonata and consequently determines the timing of population increase. While, Papadopoulos et al. (2001) indicated that the drop of temperature could be the main factor determining the end of adult activity of $C$. capitata in the area of Thessaloniki, Greece.

It is clearly to conclude that forcing guava trees for fruiting during winter season during periods of relatively low fruit fly activity through some cultural practices like irrigation preventing and hand defoliation can be effectively employed to manage fruit fly infestations in fruit. In same time, such application support local farmers for avoiding collecting the infested fruits during summer season that supposed to be unavailable under defoliation of guava trees.

\section{REFERENCES}

Afia, Y. E. (2007): Comparative studies on the biology and ecology of the two fruit flies, in Egypt Bactrocera zonata (Saunders) and Ceratitis capitata (Wiedemann). Ph. D. Thesis, Faculty of Agriculture, Cairo Univ., 301pp.

Aluja, M., and Mangan, R. L. (2008): Fruit fly (Diptera: Tephritidae) host status determination: critical conceptual, methodological and regulatory considerations. Annu. Rev. Entomol. 53: 473502 .

Amin, A. A. (2008): Ecological and biological studies on the peach and Mediterranean fruit flies in Fayoum governorate. Ph. D. Thesis, Fac. Agric., Fayoum Univ., Fayoum Egypt, 225 pp.

Boora, R. S.; Dhaliwal, H.S. and Arora, N.K. (2016): Crop regulation in guava- A review. Agricultural Reviews, 37 (1): 1-9. 
Darwish, D. Y.A.; Rizk, M.M.A.; Abdel-Galil, F.A. and Temerak, S.A.H. (2014): Analysis of factors influencing population density of the peach fruit fly (PFF), Bactrocera zonata (Saunders) (Diptera: Tephritidae) in Assiut, Northern Upper Egypt, Archives of Phytopathology and Plant Protection,

DOI:10.1080/03235408.2014.882121.

Ducky, P. F.; Sterin, J. F. and Quilci, S. (2004) : Survival and developmental of different life stages of Bactrocera zonata (Diptera : Tephritidae) reared at five constant temperatures compared to other fruit fly species. Bull. Entomol. Res., 94:89-93.

El-Baz, El. El. T.; El-Shobaky, M. A.; Lo'ay, A. A. and Saleh, M. A. A. (2011): Effect of some chemical treatments and hand defoliation on winter production as yield, fruit quality and storage life of guava. J. Plant Production, Mansoura Univ., 2 (3): $467-478$.

El-Heneidy, A. H. (2012): Status of the peach fruit fly, Bactrocera zonata (Saunders) and its control measures in Egypt. Regional Symposium on the Management of Fruit Flies in Near East Countries. Hammamet, Tunisia, 6-8 November 2012.

El-Kousy, E. M. M.; Abdel-Galil, F.A.; Amro, M.A.; Mohamed, D. S. and Shafey M. H. A. (2012): Seasonal occurrence and infestation patterns of fruit flies invading guava orchards in upper Egypt. Regional Symposium on the Management of Fruit Flies in Near East Countries. Hammamet, Tunisia, 6 $\square 8$ November 2012.

Fletcher, B. S. (1989): Life history strategies of tephritid fruit flies. In: Robinson AS, Hooper G, editors, World crop pests. Vol. 38. Amsterdam: Elsevier; pp. 195-208.

Harris, E. J.; Nakagwa, S. and Urago, T. (1971): Sticky trap for detection and survey of three Tephritids. J. Econ. Entomol., 64 (11): $62-65$.

Hashimi R. A. (2001): Insect Pest Management, cereal and cash crops. Pakistan Agriculture Research Council Islamabad, 317.
Naheed, N.; Shakeel A.; Aslam H. K. W.; Inam-urRaheem M.; Shoaib M.; Sakandar H. A. and Ramzan R. (2014): comparative study of physical and biochemical characteristics of guava fruit (Psidium guajava L.) cvs 'Gola' and 'Surahi' during summer and winter season. J. Glob. Innov. Agric. Soc. Sci., 2(2): 88-92.

Papadopoulos, N.T.; Katasoyannos B.I.; Carey J.R., and Kouloussis N.A. (2001): Saeasonal and annual occurrence of the Mediterranean fruit fly (Dipter:Tephritidae) in Northern Greece. Ann, Ent. Soc. Amer., 94: 41-50.

Pena, J. E.; Sharp, J. L. and Wysoki, M., (2002); Tropical fruit pests and pollinates: biology economic importance, natural enemies and control.Wallingford. UK.CABI. Publishing VII, 430 PP. ISBNO., 85199 - 434- 2. (Hort. Abst., 72: 10531).

Saafan, M. H.; Foda, S. M. and Amin, A. A. (2006): Ecological studies on fruit flies on different hosts at Fayoum Governorate, Egypt. Egyptian J. Agri. Res., 84(2):323-335.

Sarwar, M. (2015): Cultural measures as management option against fruit flies pest (Tephritidae: Diptera) in garden or farm and territories. International Journal of Animal Biology.1(5), 2015: 165-171

Sarwar, M.; Hamed, M.; Yousaf, M. and Hussain, M.(2014): Monitoring of population dynamics and fruits infestation of tephritid fruit flies (Diptera: Tephritidae) in guava (Psidium guajava L.) Orchard. Research and Reviews: Journal of Agriculture and Allied Sciences (RRJAAS), 3( 2): $36-40$.

Syed, R. A. (1970): Studies on the trypetids and their natural enemies in West Pakistan. Dacus spp. of lesser importance. Pakistan Journal of Zoology, 2: $17-24$.

Vayssiéres, J. F.; Sinzogan, A. and Adandonon, A. (2009): Assessment of damage caused to mangoes by fruit flies and calculation of the Economic Injury Level in Benin. IITA-CIRAD Leaflet No 7.

\section{تقلبات تعداد ذباب الفاكهة وتأثير العوامل الجوية على النشاط ومعدلات الاصابة على ثمار الجوافة في موسمي

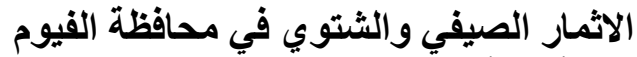

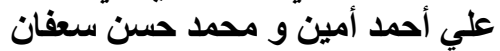

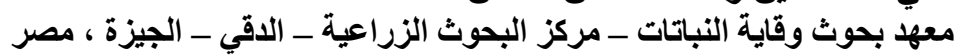

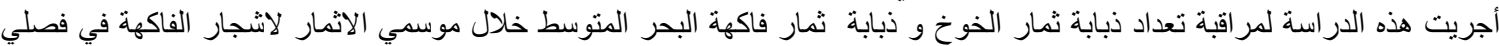

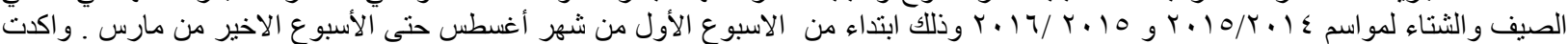

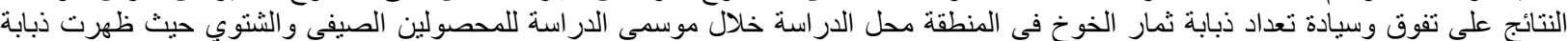

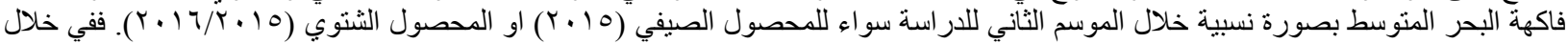

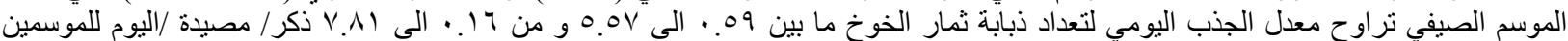

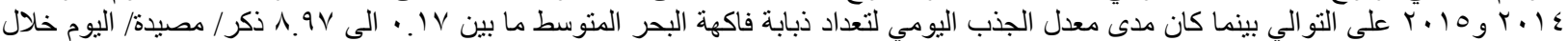

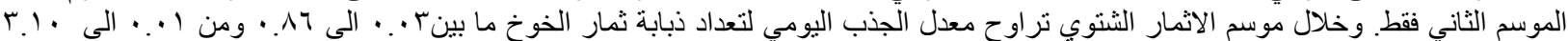

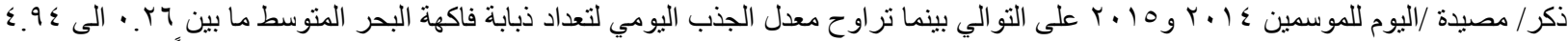

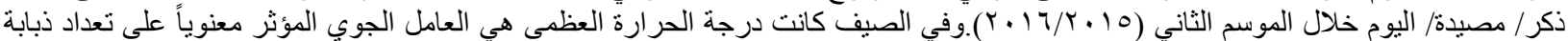

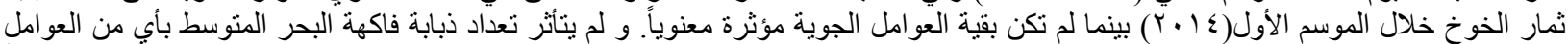

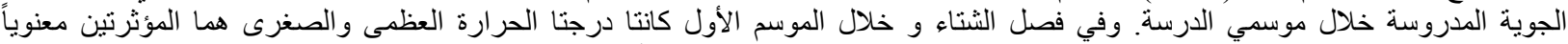

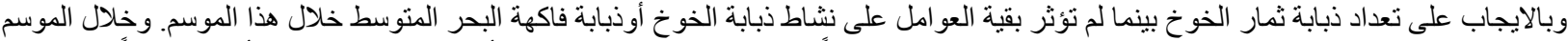

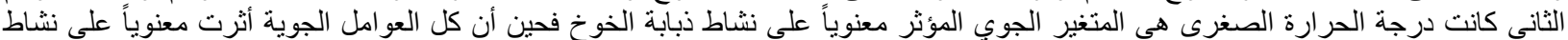

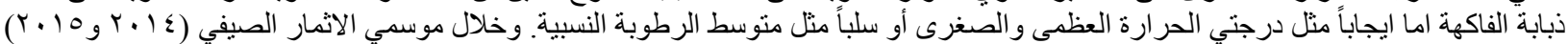

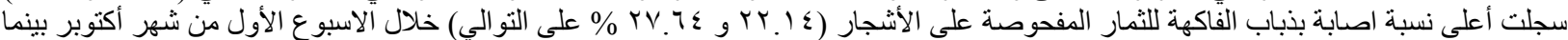

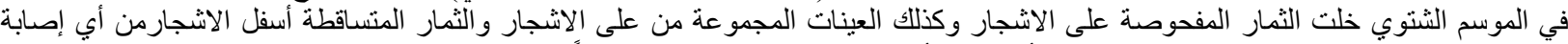

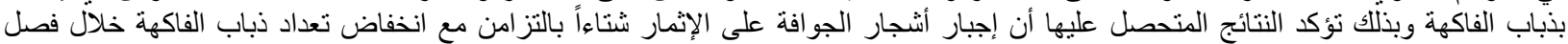

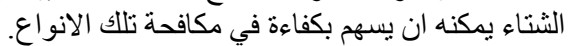

